\title{
Caminhos da Poesia Portuguesa Recente
}

\author{
Nuno Júdice \\ Universidade Nova de Lisboa
}

RESUMO: O ARTIGO TEM O OBJETIVO DE ANALISAR A POESIA PORTUGUESA CONTEMPORÂNEA, REVENDO DEBATES ATUAIS E DURADOUROS, DANDO FOCO A AUTORES IMPORTANTES REVELADOS ENTRE OS SÉCULOS XX E XXI.

ABSTRACT: THE ARTICLE HAS THE OBJECTIVE TO ANALYZE THE PORTUGUESE POETRY CONTEMPORARY, REVIEWING CURRENT AND LASTING DEBATES, GIVING FOCUS TO IMPORTANT AUTHORS REVEALED BETWEEN CENTURIES XX AND XXI.

PALAVRAS-CHAVE: POESIA PORTUGUESA - QUALIDADE - CONTEMPORANEIDADE KEYWORDS: PORTUGUESE POETRY - QUALITY - CONTEMPORARITY 


\title{
nterrogações e caminhos
}

No conjunto das vozes poéticas que marcaram o fim do século XX e o início deste novo século, há um conjunto de poetas que ocupa já um lugar que permite dizer que a poesia portuguesa continua a encontrar um caminho original na sua relação com a escrita.

Comecemos por Fernando Pinto do Amaral que consegue combinar uma visão realista, por vezes ácida, do comportamento e dos hábitos da sua geração nessa viragem de século em que a ambição de dinheiro e de poder, a que se acrescenta a moda, se tornaram o motor da vida quotidiana. O poeta usa um lirismo que, na sequência de outros poetas dos anos 80, como Luís Filipe de Castro Mendes, recupera as formas clássicas, do soneto à ode, combinadas no entanto com poemas mais descritivos e que incidem sobre o registo de factos da vida :

\author{
"Seriam oito e meia ou pouco mais \\ quando chegámos, prontos a assistir \\ ao lento fim da tarde sobre o cais \\ com o estuário do rio a seduzir \\ o ameno convívio das pessoas \\ cumporimentando a Ana Salazar \\ e comentando como estavam boas \\ as tapas de pâté e caviar. (AMARAL, $2000: 472$ )
}

Pinto do Amaral interroga o movimento dos seres e procura dar-lhe um sentidos; mas fá-lo com uma visão lúcida e crítica em que o escalpelo dos gestos quotidianos nos coloca perante quadros que evocam o claro-escuro de um Rembrandt. Ele é também o poeta que os luminosos da existência num registo de memórias que conservam uma proximidade estreita com um presente que é uma das fontes mais importantes da sua poética

Maria Andresen retoma uma outra visão do mundo, em que a sua sensibilidade e o seu olhar sobre a vida e natureza encontram sempre um diálogo intertextual com outros poetas e poéticas, sem nunca perer a sua personalidade. Esse diálogo, pelo contrário, enriquece o modo como apresenta as coisas, e 
dá-nos muitas vezes imagens inesperadas que se tornam emblemas que guiam a leitura, por entre uma paisagem que nos é familiar em que a segura nota, à maneira de um diário, pequenos acontecimentos do dia a dia, que se tornam retratança das palavras recobre uma fragilidade do se que procura a sua força na exactidão do que o verso fixa.

Nesta poesia, viaja-se através de lugares do mundo em busca de paisagens que falem do começo das coisas - da Islândia aos Açores ; e é a substância genesíaca da linguagem que Maria Andresen trabalha que a leva a "falar" com poetas como Wallace Stevens ou Herman Melville, em que as palavras nascem dessa fonte subterrânea e marinha com uma ordem e uma pureza que deixam adivinhar o fogo primordial da sua inspiração. Essa violência, porém, Maria Andresen transmite-a com uma limpidez de expressão que representa a escolha da luz e do dia sobre a sombra e a noite, mesmo quando a morte se esconda, por vezes, sob imagens e poemas que interrogam o ser :

"Como se deslizássemos para um fundo ouvindo ainda os sons de um vento que seu ímpeto colheu na insuficiência" (ANDRESEN, 2006: 91).

Em Pinto do Amaral e em Maria Andresen temos uma depuração e uma busca da linguagem, comum que também se encontra em Ana Luísa Amaral, cuja obra adquiriu já uma consistência incontestável como uma das mais representativas da escrita poética contemporânea.

Fuga ao tempo, procura de um tempo em que o tempo não conte como limite do humano, a poesia trabalha no lugar desenhado pela palavra em que as fronteiras se abrem para além de nós, e da nossa duração. É por isso que existe um conflito permanente entre a poesia e o quotidiano, a poesia e o presente, o que obriga o poeta a situar-se em função desse confronto que a pintura retratou na mulher com duas faces, a beleza e a morte, de que o barroco fez um dos seus grandes temas.

Ana Luísa Amaral situa-se nesse espaço de problematização do efémero eterno que é o poema. Esta questão joga-se num dos seus títulos: Entre dois rios e outras noites" (2008), em que a metáfora do rio heracliteano, o tempo, se recoloca na sua realidade fluvial. Temos o "topos" filosófico; mas ao contrário do movimento para a abstracção desse fragmento grego Ana Luísa 
recoloca-nos no ponto de equilíbrio que inverte o caminho, fazendo descer o olhar para a corrente verdadeira de um rio que é o verdadeiro motor das imagens que nascem do seu curso. Por isso, o título completa-se através de uma analogia quase imperceptível - "e outras noites", em que o adjectivo "outro", investido de múltiplas conotações, da diferença plural dos seres até à alteridade pessoana, coloca o rio e a noite no mesmo plano semântico.

Poderíamos dizer que há dois focos de atenção neste livro: o presente, ligado ao "êxtase" que percorre o início do livro ("se tudo fosse só êxtase súbito (7 andamentos)" (2008: 9-13) e "os perigos do êxtase") (Ibid., 17-33); a "espacialização" do tempo num bloco central situado "deste lado do tempo" (Ibid., 45-68); e um movimento rumo ao passado em que o título adquire uma variante, "entre dois rios e muitas noites" (Ibid., 71-92), que introduz a ruptura da semelhança rio-noite, desfazendo esse nó górdio que reduzia o tempo à noite com a separação desses "dois rios", que remetem para a ordem cronológico do curso temporal, e da noite, em que o tempo se torna caótico através de uma multiplicidade não especificada ("muitas noites"), acrescentando uma nova antítese polar entre dois e muitos.

E a partir daqui se atingem "os teares da memória" (Ibid., 95-113), esse passado visto como o tear, no tópico homérico de Penélope, em que esse tear - trabalho que desfia as linhas do passado - não é senão o remeter do antes para o futuro regresso de Ulisses. Por fim, "o futuro do passado" reconduz à citação pessoana do "guardador de rebanhos" de Caeiro, em que os rebanhos são feitos de "sonhos e além: o guardador" (Ibid., 117-124), isto é, essa matéria que é feita de condensações de uma experiência anterior - os objectos do mundo onírico - deslocando-os para o "além" dessa experiência que são o poema, as palavras.

Livro complexo na sua estrutura semântica, "Entre dois rios e outras noites" coloca-nos, porém, perante um universo nítido, construído por "decisões versificadas" (Ibid., 17-18) que juntam no mesmo plano "leve perfume", "gotas de limão", e a "magia calma" (Ibid., 17), como se a alquimia do verbo saísse da "estação infernal" do Rimbaud para arder num "suave lume controlável" (Ibid., 17) que não evita a "música menor" (Ibid., 24) nem os "alexandrínicos dilemas" (Ibid., 26-27) que por vezes conduzem à fratura, ao verso saindo "como vulcão/limitado a explodir dentro do mar" (Ibid., 27). Diria que esta poesia tem o rigor do Valéry sem o seu metódico e atento classicis- 
mo, e as erupções mágicas de figuras carnavalescas - no sentido bakhtiniano do termo - fazendo dançar de forma rabelaisiana os virtuosismos formais da tradição clássica: dos "diabos a monte" (Ibid., 29) às "bicharocas" (crocodila, leoparda, lémure, e a própria "Autora Derramada"/que é de nome ausente,/ como convém a pós-moderna autora") do "Livro do Hospital (1ª e última série)" (Ibid., 30-31).

Epifania negativa, esta revelação do que o tempo tem no seu reverso - a dor, a morte (as mortes) - acompanha o percurso ascendente que tem na escada de Jacob uma envolvente alegórica, mas não permite mais do que entrever o outro lado, o sol, através da fractura que separa os dois mundos, o dos vivos - lunar, a caverna platónica - e o paradisíaco, no sentido de Dante. E é nesta dimensão des-sacralizante que o poeta regressa a este mundo, a uma realidade descrita de um modo sequente e quase substantivo, entre o fulgor iluminante, por vezes, e o rigor do compasso com que Newton organiza o mundo. Desconjunção, desafinação: são os pólos que fazem rodar esses "teares da memória" onde irá surgir a "teia de espelhos" (Ibid., 113), o poema, que une as imagens caóticas no espaço que Mnemósine governa.

É este, finalmente, o mundo da poesia de que Ana Luísa Amaral desenha um exacto perfil geográfico, numa invocação do universo pastoril de onde, segundo os gregos, nasceu a arte lírica. Governado pelo "pastor-estatuário" (Ibid., 117), é este o espaço do sonho que nos reflecte, de nós divergindo na sua total autonomia:

"E tudo era num longo emaranhado

como imensa floresta,

mas as figuras vivas ali estavam,

em nítido fulgor,

transparência de um astro que brilhava,

mas que não era a lua, nem o sol, nem estrela da manhã." (Ibid., 119)

Neste regresso à "floresta dos símbolos" de Baudelaire a aproximação de Ana Luísa Amaral é outra, reconhecendo a linguagem que as coisas falam, e restituindo-lhes o seu enigma, substância e origem da imagem poética: 
"Melhor assim", pensou.

"Não me pedem um nome estas figuras

e o tempo sobrará

para mais sonhos". (Ibid., 119)

É este o fecho, e a lição, desta poética: o desejo de viagem no seu "mais vivo navio" (Ibid., 124).

Viagem, também, mas no plano da linguagem, e em direção ao inconsciente, é o que encontramos na poesia de Manuel Gusmão que nos lembra algo que parece perdido neste nosso tempo sujo: que a poesia é, antes de tudo o mais, canto, ou seja, um espaço amplo de som e de sentido em que coincidem a música, a palavra, e sobretudo a ampla respiração que irá conduzir o verso a essa totalidade em que surge "a possibilidade da imagem". (Se uma errada interpretação do lirismo, concentrando a expressão numa pequena parte do que é o "homem sensível", reduziu o poema a uma filigrana afetiva, de onde se tem partido numa poesia mais contemporânea para concentrar cada vez mais o poema num devaneio circunstancial de referentes esgotados, é num outro grupo que Gusmão se situa: esse que nasce de Herberto Hélder, passa por Ruy Belo e Al Berto, e prolonga no fundo aquilo que é a lição camoniana das "Canções", ou pessoana das Odes, em que o poema amplia o canto à dimensão total do homem, no seu registo do mundo como espaço de reflexão, simultaneamente especular e filosófica, do ser. Pode ler-se "Migrações do fogo" (2004) como um poema único - uma Ode, de que o sujeito é o Homem, no início do seu caminho, recomeçando uma aventura que vai da antiga Grécia ao "monte dos vendavais", passando pelas casas, pelo cais onde queimaram o jovem rapper, por espaços interiores ou exteriores, numa viagem em busca da identidade que o tempo, as leituras, a História, enredaram no labirinto a que se chega, descobrindo que o último passo para o centro é o início de uma nova arrancada:

"Cada parede a que chegas é agora sempre a última:/ a última parede do labirinto.” (GUSMÃO, 2004: 81-90).

Assim, o que Manuel Gusmão vem confirmar, é que a poesia continua a trazer no seu interior "a pavorosa ilusão da eternidade", quando esse último 
passo nos leva para o outro lado do mundo, obrigando ao recomeço; daí o retomar cíclico do mesmo, para que o desconhecido volte a ganhar um sentido familiar para quem escreve: ecos adjuvantes do percurso, "uma pedra na infância" que Ruy Belo terá lançado, ou "As variações do branco" que Eugénio de Andrade pintou com a cal dos seus poemas, ou essa "Canção última" que fecha, numa narrativa epilogar, a "odisseia" humana, no ponto final em que "tudo poderá talvez recomeçar" (Ibid., 90).

\section{A invenção da pólvora numa poesia sem qualidades}

Na passagem do século XX para o século XXI surge uma nova geração de poetas que, ao contrário do que sucedeu noutros períodos, não se pode considerar um grupo homogêneo, onde possamos ver um programa e um projeto. Há coincidências, mas estas resultam acima de tudo de temáticas afins e de uma relação com o passado que diverge de gerações onde seria possível encontrar um apoio na tradição da poesia portuguesa, e em "mestres" que serviriam de referência e de modelo, como sucedeu no momento do "Orpheu", no momento da "presença", e em fases posteriores. Há, sem dúvida, um grupo que se apresenta com a designação de "poetas sem qualidades", e que poderia ser visto como o mais coerente dentro desta época, mas aquilo que os distingue não é tanto uma proposta estética como a aparente rejeição de um pensamento poético, de um paradigma formal, o que vai resultar num simples epigonismo daquilo que de melhor existe nos seus referentes. De fato, não é possível constituir um grupo apenas pela rejeição; e muito menos por uma identidade assente na superficialidade de meios e recursos que, indo buscar o seu objecto ao quotidiano, ou a intertextos de poemas lidos apressadamente em antologias, fazem do poema um mero apontamento impressionista que pouco mais é, na maioria das vezes, do que uma sentimental e subjetiva confidência que estaria muito bem num diário de adolescência.

Pretende-se, no entanto, atingir com esta proposta aquilo que marca o centro da criação poética: uma consciência do ato de escrita, e o domínio pleno da técnica e dos recursos retóricos que, quer se queira quer não, não podem ser ignorados por quem escreve, sob pena de se cair no amadorismo. Este conceito simplório do que é a poesia, porém, tem vindo a ser valorizado em 
certos meios da crítica portuguesa (o que, deva dizer-se, só tem vindo a reforçar o seu descrédito) e da própria universidade (que nem sempre consegue libertar-se de simpatias que também nada contribuem para a objetividade do campo analítico). Temos aqui uma contaminação da crítica por aquilo que, de certo modo, marca o conflito de gerações: o complexo de Édipo. $\mathrm{Na}$ literatura portuguesa isto sucede porque um dos aspectos que caracteriza a nossa poesia é o fato de haver poetas que vêm de gerações anteriores, desde os anos 50 e 60, e que continuam a publicar obras perfeitamente inovadoras - lembremos Pedro Tamen, Herberto Hélder, António Osório, Gastão Cruz, Vasco Graça Moura, entre outros - sendo esta longevidade poética vista por alguns mais novos como algo de negativo, vá-se lá saber porquê.

O que se verifica, no entanto, é que existe um preconceito antilírico e antidiscursivo que apenas tem como fundamento essa ignorância daquilo que é o poético tendo por vezes, como conseqüência, um prosaísmo que embebe de cacofonias muitos destes poemas. $\mathrm{O}$ interesse deste epifenômeno, então, limita-se ao documental que, um dia, se reduzirá a uma nota de rodapé, ou nem isso, nalguma futura história da literatura. Assim, passando por cima dos "poetas sem qualidades, vamos antes na direção do que poderia ser positivo neste propósito: a possível existência de uma "poesia sem qualidades". Também aqui os equívocos são mais do que óbvios. Se lermos "O grau zero da literatura” de Roland Barthes veremos logo que esse grau zero é, afinal, um resultado de uma pluralidade de processos que implicam um conhecimento profundo da escrita e da tradição literária; e a procura de uma expressão "branca", esvaziada de esteticismo, tem sido uma constante desde que os modernismos se lançaram contra o refinamento simbolista e decadentista. Por isso, a única forma de afirmar esta "des-qualidade" poética é transformála numa crença, indo colocar como seus tutores alguns que não se cansam de apregoar, como Jeremias modernos, o fim da poesia, a morte da literatura, etc. E tal como sucede a Santo Antão, no seu deserto, as visões do mal multiplicam-se de cada vez que um novo livro ou um poeta diferente deles surge no horizonte, logo excomungados como demónios.

Poderíamos, por outro lado, dizer que se trata de inocentes, situados na doce ilusão daquilo que em Espanha se chamou a "poesia da experiência" e que mais não foi, em muitos casos, do que a procura de transformar o poema num simples relato documental de vivências mais ou menos líricas, mesmo 
quando inscritas na marginalidade ou na abjecção. Aqui, porém, cai por terra a própria afirmação de princípio, dado que a "falta de qualidades" que seria essa "inocência primordial" no contato com a escrita, com a linguagem (como se esta permitisse alguma inocência a partir do momento em que a literatura lhe confere um efeito mediador) nasce, afinal, da inscrição no que é um movimento, esse completamente estruturado e teorizado, que é esse grupo castelhano da "poesia da experiência" que visa associar o próprio leitor à experiência do poeta; o que implica, como é evidente, que este seja capaz de ter tido essa vivência, e de a fazer passar da vida para o poema. O que temos aqui, de certo modo, é uma poesia "pós-poética", ou seja, a transposição serôdia para o campo literário daquilo que, em certo momento da história do século XX, após a queda do muro de Berlim, se designou como o "fim da história". Este "fim da poesia" nasceria do apagamento das fronteiras do "poético", do fim das literaturas nacionais. O que é curioso, por outro lado, é que uma vez mais a tradição volta a galope por onde menos se espera - e nesta idéia do poema como experiência voltamos à velha "literatura viva" que o José Régio, na "presença", contrapunha à "literatura livresca".

Quem queira refletir sobre a relação entre poesia e programa, entre manifesto e resultado estético, nos movimentos literários, verifica muitas vezes a existência de contradições e equívocos na passagem da teoria à prática. Há sem dúvida um culturalismo básico nesta escrita, que começa pelo próprio título que vai buscar ao "Homem sem qualidades" de Musil a sua designação. Este culturalismo prolonga-se em muitos poemas que vivem de citações directas ou intertextuais. A autoridade de músicos, poetas, filósofos, todos surgidos da "grande" esfera do estético (Bach, Benjamin, Baudelaire) retiram assim todo o caráter "espontâneo" que essa ligação vivencial ao quotidiano pressuporia. Não surpreende que seja aqui que alguma crítica mais requintada vá buscar o alimento para a sua especulação, que funciona no conhecido esquema da "pescadinha de rabo na boca": a poesia que alimenta o poema que alimenta a poesia, etc. É, de certo modo, este recurso a textos anteriores e posteriores ao próprio poema, uma forma de prolongar aquilo que, muitas vezes, é uma incapacidade de desenhar e fechar o seu universo próprio, bem como de o sustentar numa estrutura imagética e verbal sólida, o que talvez explique a aversão que manifestam para com o que chamam "discursivismo", implicando o poema longo - embora não se compreenda porque, por um 
lado, rejeitam Ruy Belo, e por outro reivindiquem Herberto ou Cesariny, poetas em que esse discursivismo é integrante das suas poéticas.

Depois de referir apenas o aspecto programático deste setor da nova poesia portuguesa, sem entrar em juízos sobre o valor relativo de cada obra poética individualizada, onde há sem dúvida graduações de qualidade e uma complexidade de cada universo que importa ter em conta, passarei ao levantamento de alguns aspectos comuns ao que se poderá designar como a geração do novo século - englobando um conjunto que vai além do grupo anteriormente referido, e que muitas vezes nem tem qualquer relação com ele.

Um primeiro topos que se repete é o da escrita, entendida não como objeto mas como "ato de escrever". A escrita é como que uma condenação a que o poeta se sente obrigado, não se sabe porquê, resultando daí como que um suplício masoquista dado que o ato simples de rejeitar tanto a escrita como aquilo para que ela pode arrastar o poeta - uma "vida literária" e um "reconhecimento" que são apresentados como algo de insuportável, dado que anulam essa existência "sem qualidades" no momento em que a crítica lhes reconhece uma qualidade - a de fazerem parte da literatura e, pior ainda, da "literatura portuguesa", abominação derradeira. De fato, o que temos é essa santificação do gesto rimbaldiano de abandonar a poesia, por outro lado, e do apagamento herbertiano do sujeito: dois modelos que funcionam como o nec plus ultra de um heroísmo que só não se realiza porque, no fundo, ninguém lhe atribuiria grande interesse dado o gratuito e o absurdo repetitivo do gesto.

A esta patologia do literário vai somar-se o topos horaciano do carpe diem que surge não tanto da angústia do tempo que passa e da luta contra a brevidade da vida, mas associado ao desejo de prolongar a juventude, ao horror de um envelhecimento que se liga não apenas à morte mas também a esse sentimento abominado que é a melancolia; e se a ele juntarmos a "saudade", teremos dois dos fantasmas de que se procura um esconjuro por estarem ambas - melancolia e saudade - associadas tradicionalmente a um modo de "ser português" antiquado e pretensamente ultrapassado. Daqui decorre a ideia de um certo sentimento de "orfandade" que é procurada, quer naturalmente quer pela sua inscrição num mundo de perda em que as referências familiares surgem ligadas à morte de pais ou avós que são lembrados, ou de espaços de infância que se perderam de modo irreversível, sem possibilidade de substituição. É também uma forma de associar o registo autobiográfico ao 
poema, na linha de um Baudelaire que em certos momentos aparece como figura tutelar de uma "maldição" quase sempre demasiado construída. Por vezes, nos casos piores, isto resulta num artesanato em que as mitologias pessoais aparecem num jogo heteróclito com uma invenção de situações banais, produzindo o artificialismo de sentimentos e desfechos onde é mais evidente a procura do efeito poético do que do poema.

Este sentimento de perda da infância e do mundo familiar acaba, então, por resultar num contraste com o mundo actual onde o adulto nos aparece como algo de incompleto, sendo o poema uma constante afirmação desse negativo que é o presente sem antes nem depois, oximoro disfórico do próprio ser. Esta recusa do tempo que passa vem, por outro lado, de um outro aspecto na relação com o real. Este é sempre uma degradação do ontem; e esta degradação é um processo imparável, numa visão política (não assumida, mas conservadora) que decorre da sensação de fim do país, da literatura, da cultura, da paisagem, etc., que Umberto Eco descreveu no "Apocalípticos e integrados", onde todos estes fenômenos se encontram perfeitamente esquematizados - com a diferença de quem nem sempre, para não dizer quase nunca, os apocalípticos são os "desintegrados".

Tudo isto é apresentado como algo de inevitável, sendo o poeta o espectador passivo de uma degradação que, paradoxalmente, o alimenta, como ave de rapina da miséria do mundo no seu registo de acontecimentos feito com o tom superior e crítico de quem paira acima das populações ignaras. Esta revolta, então, não passa de um conformismo que decorre da impotência em vencer a invasão do "mau gosto", da cultura do shopping e do condomínio sobre o mundo paradisíaco de um Poético que, não podendo existir dado que o ideal de beleza que lhe está associado é proscrito neste universo, transforma o poeta num Mr. Hyde do quotidiano. É portanto uma revolta que, paradoxalmente, se converte num conformismo que decorre da impotência em vencer esse progresso, que nasce da prosperidade (e da propriedade) democráticas, mas sobretudo da banalização do quotidiano que apaga a memória de um passado heróico e paradisíaco, que outras gerações puderam utilizar como parte da sua experiência.

Perguntar-se-á se há uma saída para este desânimo? Sem dúvida, mas talvez seja difícil assumi-la dado que isso representaria o fim deste projeto. Ela não se encontra no "regresso ao real", que é algo de perfeitamente corrente na poesia 
contemporânea, para não falar das últimas décadas do século XX e, sobretudo, do grupo de poetas surgidos nos anos 90, mas no "regresso à qualidade". A solução está dada, coragem, poetas sem qualidades: é só mais um passo!

\section{Rumos do novo século}

Podíamos dizer que a poesia tem horror ao vazio; e é assim que, já na primeira década do século, surgem propostas inovadoras, tanto a nível individual como colectivo. A abertura para o que se poderia chamar uma "nova geração" é a publicação da revista "Criatura", que, depois de um primeiro número publicado em 2008, em 2009 chegou ao terceiro número. Dirigida pelos poetas Ana M. P. Antunes, David Teles Pereira e Diogo Vaz Pinto, nela se reflete uma relação com a poesia que decorre de um mundo de leituras e de inter-relações que vai buscar ao universo de língua inglesa, por um lado, e à poesia ibérica e latino-americana, por outro, os seus referentes mais impressivos. Já este fato - tratar-se de poetas que lêem poesia - contribui para os distinguir de uma negativa tendência para o fechamento e o esgotamento que noutros se tornara visível. Há uma consistência de linguagem e de projeto nesta revista que se pode somar, sem dúvida, à qualidade individual de cada poeta, onde surgem também algumas vozes femininas que vão ao encontro de revelações interessantes do mesmo período: Filipa Leal, Catarina Nunes de Almeida e , mais recentemente, Joana Serrado.

O que caracteriza estes poetas é a procura de uma expressão própria, por um lado, e o regresso a uma relação pessoal com o seu tempo e o seu mundo, liberta de imposições de escola, de estilo ou de moda. A este conjunto poderia também acrescentar-se um conjunto de nomes que apontam percursos próprios: Rui Lage, Rui Cóias, Rui Pires Cabral, José Mário Silva, e um poeta que publica há mais tempo mas que atinge também um ponto interessante neste período: João Luís Barreto Guimarães. Igualmente interessante é verificar que há também alguns poetas que prosseguem a coexistência com a ficção que já no século XX fora constante em vários grandes autores: refiro-me a valter hugo mãe, a José Luís Peixoto e a Gonçalo M. Tavares.

Não irei aqui falar em pormenor de cada poética, mas o que julgo importante é acentuar a diversidade deste conjunto já importante do que se pode 
chamar uma poesia do princípio de século, com uma diversidade de linguagens que permite começarmos a ter uma visão não só geracional como estética dos caminhos que se estão a abrir, e de que alguns destes nomes serão, sem dúvida, os representantes.

\section{Referências Bibliográficas}

AMARAL, Ana Luísa. Entre dois rios e outras noites. Porto: Campo das Letras, 2008. AMARAL, Fernando Pinto do. Poesia reunida (1990-2000). Lisboa: Dom Quixote, 2000. ANDRESEN, Maria. Livro das passagens. Lisboa: Relógio d'Água, 2006.

ANTUNES, Ana M. P. et alii (org.). Criatura. Núcleo Autónomo Calíope da Faculdade de Direito de Lisboa com o apoio da Associação Académica, 4 ns.

GUSMÃO, Manuel. Migrações do fogo. Lisboa: Caminho, 2004. Relâmpago, no 12, 4/2003,

"Nova poesia portuguesa", Lisboa, ed. Fundação

Luís Miguel Nava, Lisboa. 